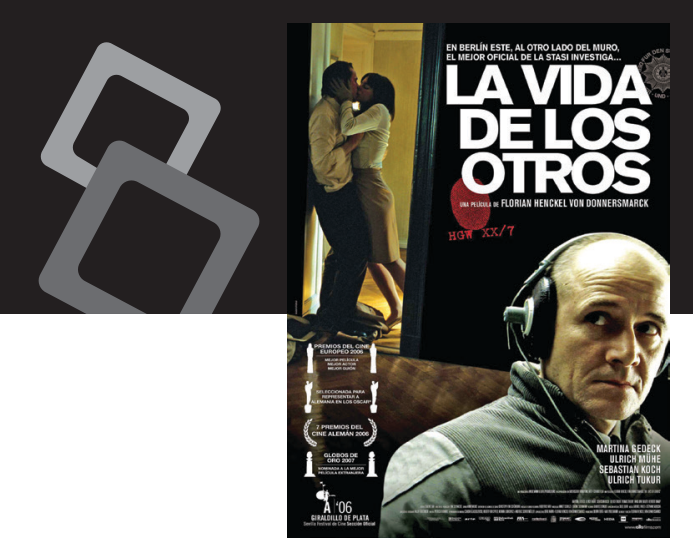

TÍTULO ORIGINAL:

"Das Leben der Anderen";

AÑO: 2006; DURACIÓN:

137 minutos;

PAÍS: Alemania; DIRECCIÓN

Y GUIÓN: Florian Henckel von

Donnersmarck;

\title{
PRODUCCIÓN EJECUTIVA:
}

Quirin Berg, Max Wiedemann;

DIRECTOR DE FOTOGRAFÍA:

Hagen Bogdanski; MÚSICA

ORIGINAL: Gabriel Yared,

Stéphane Moucha;

GÉNERO: Drama.

\section{La vida de los otros}

La inteligencia es una disciplina científica que genera un conocimiento anticipado para orientar la toma de decisiones de los operadores políticos en general, así como las acciones de todos aquellos actores que intervienen en la confección de respuestas. Esta disciplina no puede ni debe reducirse al recurso de espionaje, que constituye una práctica histórica y clásica con la cual se ha movilizado la búsqueda de información; situación que ha permitido qué cursos de acción tomar en un momento dado. Esto último como resultado del conocimiento aproximado que se ha obtenido acerca de los adversarios y su contraposición con las posibilidades propias.

La inteligencia se ha desarrollado en distintos campos, dimensiones y ámbitos. Uno de ellos, quizá el más conocido, ha sido el de la política. Por las razones que fuesen, lo cierto es que los Estados y gobiernos han comprometido recursos humanos para estas tareas, generando en el proceso prácticas envolventes y amplias que han permitido la vigilancia y radiografía, por ejemplo, de los opositores al régimen. La categoría es sumamente diversa en su contenido cualitativo, pues encierra un grado de disidencia que concierne al nivel de tensión que algunos actores tengan contra el estado de cosas imperante y la voluntad para cambiarlo. De allí que la "Inteligencia Política" a secas deviene en todo un andamiaje de observación, registro y seguimiento de los opositores en una sociedad determinada. Estos pueden ser visibles y emplear los canales previstos por el régimen, o pueden ser menos visibles en sus distintas alternativas. Es decir, resisten el poder del Estado o son defenestrados y ubicados como potenciales enemigos del orden establecido. Esto es, por supuesto, un hecho subjetivo que se robustece en la medida que la dinámica de estímulos y respuestas de quienes se enfrentan se conduce por causes de alta conflictividad social o enfrentamiento político. Y más importante aún, se origina por el convencimiento real o perceptivo de las élites del poder, de que su autoridad está amenazada o podría estarlo. 


\section{CINE}

El film "La Vida de los otros", del director Florian Henckel Von constituye una producción cinematográfica contemporánea que lleva implícito un ejercicio retrospectivo de la sociedad alemana. Por primera vez, se logra retratar la realidad sobre la absorbente atmósfera de la vida del ciudadano común en la ex República Democrática Alemana (RDA). Desarrolla una trama ubicada en la primera mitad de los años ochenta, auge de lo que algunos especialistas y políticos dieron en llamar la neo contención o segunda guerra fría, caracterizada por un ambiente político y diplomático tenso en toda Europa.

La decisión del mando estratégico norteamericano de desplegar una nueva generación de misiles nucleares en sus bases en Europa, sustituir los viejos Minuteman por los Pershing $I /$, desató un ciclo de protestas públicas en occidente, que poco importaban para el ciudadano promedio, si ello había sido la respuesta a una medida similar implementada por los soviéticos en sus bases estratégicas de Europa Oriental. Sin embargo, el creciente nivel de conciencia política en estos movimientos, acerca de las consecuencias de estas espirales de armamentización, puso también en alerta a la clase política y dirigencias en los países del socialismo real. Situación que condujo a esfuerzos renovados de los aparatos de seguridad e inteligencia para prevenir disidencias y otras amenazas que pusiesen en riesgo los objetivos de la política oficial. Este es el contexto internacional y continental imperante del período que se presenta en el film; la Stassi, policía política del régimen alemán oriental es el actor principal de contención en el frente interno.

Sociedades cerradas como las de Europa oriental de aquella época, en cuyo telón de fondo estaban las crisis y vulnerabilidades crecientes de todo el bloque socialista, -sumado el estancamiento económico y la decadencia de la Unión Soviética para seguir sosteniendo nuevas iniciativas estratégicas y mantenerse en la competencia geopolítica y la lucha por el liderazgo global-, eran aspectos del conocimiento de las élites del poder en esos Estados, pero que esa situación se conociera en sus sociedades y ciudadanía constituyó un objetivo de seguridad vital para prevenir crisis y fisuras en el régimen.

En el contenido del film se identifican tres grupos de actores. Estos son, en su orden: Los burócratas del partido, los operadores del aparato de inteligencia y los ciudadanos comunes, estos últimos representados acá por intelectuales, un segmento de población muy vigilado por el régimen. Este énfasis resulta obvio, si se tiene en cuenta que el intelectual no comprometido deriva en crecientes grados de autonomía política; su acervo cultural y académico lo hacen menos susceptible a la propaganda y grandilocuencia oficial, y por lo tanto, aunque prevalezcan entornos adversos e incluso hostiles, se generan en él condiciones para el pensamiento propio y crítico. 
Este es el caso de una pareja de intelectuales, ella actriz teatral y su cohorte escritor y ensayista (George Dreyman y Christa María Sieland, respectivamente). Ambos viven un aprisionamiento social por ser parte de la élite cultural, son observados y devienen en blanco de las operaciones encubiertas de inteligencia política por parte de la Stassi. Los objetivos son bastante indeterminados, se adentran desde saber los conflictos y desencuentros en la intimidad de pareja, hasta descubrir supuestas lealtades ocultas con filiaciones políticas distintas a la oficial. Los dos son exitosos en su ámbito profesional, sin dejar de considerar que esto forma parte del estándar del régimen para definir y presentar buenos ejemplos entre sus ciudadanos. El seguimiento es omnipresente, a la instalación clandestina de micrófonos en el lugar de habitación de ambos y la complicidad de los vecinos, la Stassi cuenta a cabalidad con grabaciones diarias de conversaciones, recurso que les permite levantar expedientes, una práctica muy difundida en la RDA de ese entonces. Este país de 16 millones de habitantes llegó a tener un archivo nacional, en el que prácticamente todos los ciudadanos habían sido espiados. Un recurso de control social, inherente a todo régimen que pretende persistir como sistema y prevenir el efecto nocivo de la turbulencia política.

Los ciudadanos transformados en víctimas no se sustraen de sus propias miserias personales, ante la imposibilidad de que la realidad cambie y la falta de concreción de la felicidad como realización y aspiración personal e interior, más allá de los recursos previstos de una sociedad cerrada e hiper vigilada, caen en un vacío existencial que deviene en cuadros depresivos. Se presenta la evasión, comportamiento que lleva a la actriz al suicidio prematuro (Christa María Sieland); consecuencia del peso irresoluble de su culpa por prestarse a la práctica corrupta de un burócrata del partido (representado en el Ministro del Buró Hempf), que no tiene escrúpulos para extorsionarla, incluso sexualmente. Convertida en caballo de Troya, para erigirse como la operaria en la línea primaria de observación y vigilancia, el remordimiento moral se vuelve un asunto imposible de manejar.

Por su parte los operarios del aparato de inteligencia (Gerd Wiesler), se presentan acá como tecnócratas fríos convencidos que sirven a una causa superior; asumen que su moral política está ampliamente justificada y que la misma les faculta para el recurso de la violencia; ejercido este contra todos aquellos que identifican como inadaptados. Se presentan varios aspectos que vale la pena retratar. En primer lugar el perfil del personal de inteligencia, este acude a una universidad que forma a sus cuadros en esta especialidad; algunos de sus operarios, como el protagonista en este caso, asumen sus responsabilidades más allá del umbral normal de exigencia 


\section{CINE}

de sus jefes políticos. Estos se presentan ante los nuevos que están siendo formados, como inexpresivos, no se tolera ninguna inquietud por ingenua que parezca; y que podría volverse susceptible de cualquier investigación o apertura de expediente. Destaca el episodio donde el experimentado y veterano jefe de sección en la Stassi (Gerd Wiesler) imparte una clase a operarios en formación, y la postura, demasiado franca y autónoma de uno de los alumnos en torno al manejo de los prisioneros que han sido privados de sueño por muchas horas, despierta la sospecha del profesor por percibirse como incongruente con el carácter con el que se busca formar. Exagerado o no, lo cierto es que este burócrata de la inteligencia tiene sus propios hastíos, actúa en su vida personal como aquel tipo contemplativo del orden de cosas, de la cual él y otros se asumen como garantes. En el fondo pareciera mostrar que esa realidad maquillada se desmorona por sí sola, que consumir y monitorear diariamente la propaganda oficial y toda la parafernalia, lo ha robotizado y movilizado por los causes del cumplimiento del deber.

Este frío operario pareciera ser el prototipo de los hombres responsables de la seguridad del Estado, pero no lo es. A su vida gris y rutinaria, arrastra consigo represiones sexuales, que se vuelcan al uso de crecientes mecanismos sociales de prostitución, algo que en lo políticamente correcto del régimen sería inaceptable e improbable.

El seguimiento que este operario de la inteligencia política hace de la pareja de artistas, le desarrolla un vínculo de sensibilidad y afinidad hacia las víctimas en una lógica cercana y lejana. La primera porque sabe todo de ellos y la segunda porque contribuye a modelar los episodios de vida de las víctimas, situación que expresa una especie de mayordomía en una sociedad controlada y altamente dirigida. En la trama se produce un quiebre de cotidianidad en las tareas de vigilancia, mediando una extraña identificación con la víctima y las desgracias de su pareja; este frívolo operario permite, sin sobresaltos, la entrega por parte del escritor de un ensayo sobre el suicidio en la RDA. El trabajo llega a un medio de Alemania Occidental y sus impactos causan revuelo en los dirigentes del otro lado del muro. Se suceden acciones encaminadas a buscar a los responsables de tan notable fuga de información y por lo tanto negligencia en el aparatchiki gubernamental. Este experimentado agente de inteligencia no es, sin embargo, infalible a sus propios fallos, sobre todo si se los propició con cierta libertad y discrecionalidad. Las consecuencias son evidentes, el cuadro ejemplar, es degradado y recluido a actividades administrativas de menor orden; un castigo que rectifica la indisciplina de uno de sus miembros, a través de un recurso para su veto e invisibilización. Se le separa 
de las funciones que dentro de la estructura proveían de gratificaciones y prestigio, se le sustrae del ámbito de la formación de otros agentes, porque su desacierto es visto como peligrosamente replicable y con potencial de plantearse como mal ejemplo.

Esta producción fílmica retrata poderosamente las dimensiones de la inteligencia política y los aparatos de seguridad en contextos de supervivencia de un régimen político en particular. El censo nacional, en cuanto plataforma base para el planeamiento de lo público, se convierte en objetivo de la vigilancia y el registro global de todos los ciudadanos. Identificando en el proceso a todos aquellos segmentos de potencial soporte y colaboracionismo con el régimen; y a la disidencia pacífica y radicalizada. Mediando en todo este esfuerzo general de radiografía del perfil colectivo de una población, los imperativos de mantenimiento de la paz social en el orden interno; y para ello acontecen las iniciativas del Estado para prevenir todas aquellas situaciones que lo hagan derivar en un frente, realidad paradójica que se dio en la segunda mitad de los años ochenta. Eso que se buscó prevenir a toda costa, estalló espontáneamente con un emergente ciclo de protestas públicas sumamente beligerantes que hizo tambalear, en su primera etapa, los simientos del régimen y lo derrumbó con posterioridad. No debe olvidarse que enardecidas multitudes de alemanes orientales, asaltaron finalmente la sede de la Stassi, una gran cantidad de archivos fueron destruidos, mientras que otros se conservan y pueden ser consultados, aún en la actualidad.

La experiencia de la ex RDA plantea un caso extremo de la práctica y concepción de la inteligencia política; esta es legítima como función del Estado, pero se trata de un ámbito poroso, con fronteras difusas que hacen que la línea entre el bien y el mal, de acuerdo a quien las establezca, vuelva complicado definir y justificar las acciones de respuesta y contención, contra todos aquellos que pueden pasar de la simple actividad conspirativa a verdaderos escenarios de sabotaje y terrorismo que todo Estado buscará enfrentar y revertir.

La información es poder, y si se trata de conocer las actitudes, objetivos e intereses de otros grupos sociales y políticos en una sociedad, su procesamiento es de primer orden para efectos de estimar la situación de la cohesión interna y el potencial de la unidad nacional.

Sinopsis elaborada por Juan Carlos Morales Peña Editor jefe de la Revista "Policía y Seguridad Pública" 